\title{
Prognostic Makers Including Immune and Inflammatory Factors Predict Outcomes in Patients Receiving Postoperative Radiation Therapy for Cholangiocarcinoma
}

Yuki Mukai ( $\square$ y_mukai@yokohama-cu.ac.jp)

Department of Radiation Oncology, Yokohama City University Graduate School of Medicine https://orcid.org/0000-0002-0000-1199

Ryusei Matsuyama

Yokohama City University School of Medicine Graduate School of Medicine

Madoka Sugiura

Yokohama City University School of Medicine Graduate School of Medicine

Yasuhiro Yabushita

Yokohama City University School of Medicine Graduate School of Medicine

Risa Taniuchi

Yokohama City University School of Medicine Graduate School of Medicine

Yuki Homma

Yokohama City University School of Medicine Graduate School of Medicine

Kotaro Hashimoto

Yokohama City University School of Medicine Graduate School of Medicine

Kentaro Miyake

Yokohama City University School of Medicine Graduate School of Medicine

Yuya Tabuchi

Yokohama City University School of Medicine Graduate School of Medicine

Itaru Endo

Yokohama City University School of Medicine Graduate School of Medicine

Masaharu Hata

Yokohama City University School of Medicine Graduate School of Medicine

Research article

Keywords: cholangiocarcinoma, postoperative-radiation therapy, external beam radiation therapy, 3-dimensional radiation therapy, lymphocyte count ratio

Posted Date: December 1st, 2020

DOI: https://doi.org/10.21203/rs.3.rs-115857/v1

License: @ (i) This work is licensed under a Creative Commons Attribution 4.0 International License. Read Full License 


\section{Abstract}

Purpose: This study aimed to analyze treatment outcomes and prognostic markers, including immune and inflammatory factors, of postoperative radiation therapy (RT) administered to patients with cholangiocarcinoma (CCA).

Methods: We retrospectively selected 59 patients with CCA who underwent surgery and postoperative RT with curative intent from 2004 to 2019. Patients received external irradiation (50 Gy in 25 fractions) using three-dimensional RT. Overall survival (OS), cause-specific survival (CSS), progression-free survival (PFS), and locoregional control (LRC) rates of initial RT were assessed using the Kaplan-Meier method. Univariate and multivariate Cox proportional-hazards regression models were used to identify prognostic factors. We analyzed prognostic factors of inflammation, such as pre-RT platelet count, hemoglobin, lymphocyte count ratio (LCR) of the leukocyte count, platelet-to-lymphocyte ratio (PLR), and neutrophil-to-lymphocyte ratio (NLR).

Results: Tumor stages were distributed as follows: I $(n=8)$, II $(n=25)$, III $(n=15)$, and IVA $(n=11)$. The median follow-up was 24 months. Twoyear OS, CSS, PFS, and LRC rates were $59.5 \%, 62.0 \%, 40.1 \%$, and $66.7 \%$, respectively. Univariate analysis revealed that lower LCR was significantly associated with shorter PFS ( $P=0.0446$, hazard ratio (HR): $1.90,95 \%$, confidence interval $(\mathrm{Cl})$ : $1.02-3.58)$. There was no significant difference between the median baseline values of PLR and NLR; and age $\geq 75$, positive regional lymph node metastases (N+), and chemotherapy after RT were significantly associated with poor OS. Multivariate analysis revealed a significant association of N+ with OS, PFS and CSS and that lower LCR was significantly associated with PFS (HR: $0.481, \mathrm{Cl}: 0.252-0.905, p=0.0234$ ). Among late toxicity events, two patients (3.38\%) were suspected with therapy-related liver toxicity.

Conclusions: LCR before RT was a prognostic factor for postoperative radiation therapy of patients with CCA.

\section{Introduction}

Cholangiocarcinoma (CCA) is relatively rare, although the incidence has increased to 1.9 cases per 100,000 recently [1, 2, 3, 4, 5]. Patients with CCA usually undergo surgery as initial treatment with curative intent. However, complete resection (R0) is often difficult because of frequent invasion of adjacent tissues or initial diagnosis at an advanced stage. High rates of recurrence after resection alone often requires adjuvant therapy $[6,7,8]$. The National Comprehensive Cancer Network (NCCN) guidelines [9] suggest the use of adjuvant radiation therapy (RT) with or without chemotherapy for patients with CCA with microscopic positive margins (R1), macroscopic positive margins (R2), or regional lymph node metastasis (N+). The current American Society of Clinical Oncology (ASCO) guidelines suggest that patients with extrahepatic CCA or gallbladder cancer with microscopic positive margins (R1) are eligible for chemoradiation therapy [6]. We analyzed the treatment outcomes of postoperative RT and reported the tolerance dose for the remnant liver after surgery for CCA [10]. The efficacy of adjuvant RT has been getting more common lately. However, the advantage of adjuvant RT is controversial, because certain investigators conducted retrospective studies $[11,12,13]$.

Multiple tumors, large tumor volumes, positive lymph nodes, and macrovascular invasion serve as prognostic factors for CCA [14, 15]. Further, positive lymph nodes and margins (R1) are significant prognostic factors of patients administered adjuvant therapy [16]. However, we lack universally accepted standardized prognostic factors. This situation may be resolved by evaluation of immune and inflammatory factors that serve as prognostic factors for other malignancies [17-20].

To our knowledge, the present study is the first to analyze the treatment outcomes and prognostic markers, including immune and inflammatory factors, of patients with CCA who underwent postoperative RT. We further determined the safety and efficacy of postoperative RT for patients with CCA. We previously published studies on the use of postoperative RT for CCA; however, the prognostic markers, including immune and inflammatory factors, were not considered in detail [10]. We therefore updated and reanalyzed the data of patients with CCA administered postoperative RT; and we present treatment outcomes and discuss prognostic factors.

\section{Materials And Methods}

Patients

We retrospectively reviewed the records of 59 patients with CCA who underwent radical surgery and postoperative external beam radiation therapy (EBRT) with curative intent at our institution from September 2004 to December 2018. The determination of the clinical stage was based on physical examination, chest X-ray, and computed tomography (CT). Certain patients underwent magnetic resonance imaging (MRI) and positron emission tomography-computed tomography (PET-CT). Surgeons and radiation oncologists examined all patients before treatment, and patients were diagnosed according to the International Union Against Cancer staging system. Patients' pathological characteristics are summarized in Table 1. The institutional review board of our institution approved this study (IRB number, B191100004), and informed consent was obtained from all patients before treatment.

Page $2 / 12$ 
All patients underwent radical surgery and were administered postoperative RT with curative intent. The types of resection are listed in Table 1. Pathological margins were determined through review of pathology reports. The standard chemotherapy regimen comprised combined gemcitabine (GEM), tegafur/gimeracil/oteracil (TS-1), or cisplatin. The order of chemotherapy was as follows: (a) neoadjuvant; (b) postoperative, before RT; (c) postoperative, concurrent with RT; and (d) postoperative, after RT. Thirteen patients (22.0\%) were not administered chemotherapy during these phases because of comorbidities (e.g. renal or psychopathic disorder) or advanced age.

There was no gross tumor volume (GTV) because all patients were resected primary tumor.

The clinical target volume (CTV) was defined as the primary tumor bed. The planning target volume (PTV) included set-up error, defined as a 10-15 mm margin from the CTV, accounting for respiratory motion. Photon radiation therapy was delivered using two to four beams. Patients received external irradiation, and the median prescribed total dose was $50 \mathrm{~Gy}$ (range: 43.2-56 Gy). Fraction sizes ranged from $1.8 \mathrm{~Gy}$ to 2 Gy delivered daily, 5 days per week, using $15 \mathrm{MV}$ X-rays and a shrinking field technique. The radiation filed was changed $0-2$ times according to liver and kidney tolerance doses.

Evaluation criteria and statistical analysis

Responses were evaluated according to the findings of clinical examination and enhanced CT approximately 4-6 weeks after completion of treatment. Tumor responses were assessed using the Response Evaluation Criteria in Solid Tumors (RECIST ver. 1.1) [21]. When tumor progression was not detected within the radiation field without recurrence after treatment, the disease was considered locally controlled and progression-free, respectively. Acute and late toxicities associated with treatment were evaluated according to the Common Terminology Criteria for Adverse Events v4.0 (CTCAE v 4.0, 2009) [22]. Acute toxicities were defined as therapy-related adverse events that occurred within 3 months after the initiation of irradiation, and late toxicities as those occurring after 3 months.

We analyzed prognostic markers, including immune and inflammatory factors. The lymphocyte count ratio (LCR) was defined as the percentage of the absolute lymphocyte count (ALC) of the leukocyte count, the neutrophil-to-lymphocyte ratio (NLR) was defined as absolute neutrophil accounts (ANCs) to ALC, and the platelet-to-lymphocyte ratio (PLR) was defined as platelet count to ALC. Overall survival (OS), cause-specific survival (CSS), progression-free survival (PFS), and loco-regional control (LRC) rates from the beginning of treatment were calculated using the Kaplan-Meier method. The significance of differences between curves were evaluated using the log-rank test. Analyses of prognostic factors employed univariate and multivariate Cox proportional-hazards regression models, using the Statistical Package for the Social Sciences (SPSS for Windows, version 23.0; IBM, Armonk, NY, USA). P $<0.05$ was considered significant.

\section{Results}

The median follow-up time was 24 months (range, 2-183 months). The median time between the day of surgery and initiation of RT was 77 days (range, 33-370 days), and the median overall treatment for RT was 38 days (range, 9-54 days). Fifty-eight patients completed RT without interruption, and one patient terminated RT at $16 \mathrm{~Gy}$ because of cholangitis. Chemotherapy regimens and numbers of patients are shown in Table 2.

Survival and Tumor control

Two-year effective rates were OS, 59.5\%; CSS, 62.0\%; PFS, 40.1\%; and LRC, 66.7\% (Fig. 1). At the last follow-up, 12 (20.3\%) patients were considered progression-free, and the median survival time (MST) was 29.5 months. Thirty-one (52.5\%) patients died of cancer, and 5 (8.5\%) died of causes unrelated to cancer, including heatstroke $(n=1)$, pneumonia $(n=1)$, cerebral hemorrhage $(n=1)$, and hepatic failure $(n=2)$. These hepatic failures were suspected as therapy-related liver toxicity, although they were not pathologically verified. Nine patients developed only local recurrence, and 10 patients experienced local recurrence and distant metastases.

The most frequent sites of local recurrence were the hepatectomy stump and anastomosis $(n=15)$, followed by the vicinity of the intrahepatic bile duct $(n=4)$. Twenty-three patients developed only distant metastases. The most frequently metastatic sites were the liver ( $n=15)$ and peritoneal dissemination ( $n=13$ ), including overlapping sites. Other metastatic sites were detected in the lung, duodenum, or in multiple lymph nodes.

Analysis of prognostic factors

Univariate and multivariate analyses of factors associated with OS, CSS, PFS, and LRC are summarized in Table 3 . The tumor volumes of 54 patients were analysed, and the mean tumor diameter was $40 \mathrm{~mm}$ (range, 18-100) mm. There was no significant difference between tumor size and outcomes (no data shown). Immediately before administering RT, we analyzed prognostic markers such as immune and inflammatory 
factors, including platelet count, haemoglobin, LCR, PLR, and NLR. Univariate analysis revealed that age $\geq 75$ and N + were significantly associated with shorter OS ( $p=0.0283$ and $p=0.0343)$, and $N+$ was significantly associated with shorter CSS ( $p=0.0283)$. LCR $\leq$ median value was significantly associated with longer PFS $(p=0.0446)$. However, NLR and PLR immediately before RT were not significantly associated with treatment outcomes (NLR: OS, $p=0.195 ; \mathrm{CSS}, p=0.33 ; \mathrm{PFS}, p=0.24 ; \mathrm{LRC}, \mathrm{p}=0.69$. PLR: OS $p=0.66 ; \mathrm{CSS}, \mathrm{p}=0.42 ; \mathrm{PFS}, \mathrm{p}=$ 0.26 ; LRC $p=0.98)($ Table $3-1)$.

Multivariate analyses revealed that $\mathrm{N}+$ was significantly associated with worse OS and CSS (OS: hazard ratio [HR] 1.96, confidence interval [CI] 1.043-3.727, $p=0.0366$. CSS: HR 2.125, Cl 1.084-4.233, $\mathrm{p}=0.0283)$. $\mathrm{N}+$, and LCR $\leq$ median values were significantly associated with PFS $(\mathrm{N}+$ : HR 1.962, Cl 1.015-3.837, $\mathrm{p}=0.0451$. LCR: HR 0.481, Cl 0.252-0.905, p = 0.0234) (Table $3-2)$.

Toxicity

Table 4 shows therapy-related acute toxicities. Among acute toxicity events, three patients developed mild cholangitis during or immediately after RT. Two patients developed Grade 4 neutropenia, one received concurrent chemoradiation therapy, and the other received RT alone. One patient developed Grade 4 thrombocytopenia, which were decreasing during RT gradually, and after RT, she received chemotherapy (GEM).

Before RT, patients' Child-Pugh (CP) classifications were CP class A, $n=48$ and CP class $\mathrm{B}, n=11$. After RT, they were CP class A, $n=45$ and CP class $\mathrm{B}, n=13$. (One patient discontinued RT and the CP was therefore not evaluated after RT.) Among the 59 patients, 11 (18.6\%) had lower CP scores after RT, and two patients' (3.38\%) scores improved. Among late toxicity events, two patients (3.39\%) experienced possible therapyrelated liver toxicity. Both had no evidence of local recurrence and distant metastases, both received chemotherapy before and after RT (TS-1 and GEM), and they died of hepatic failure. Except for these two patients, other treatment-related late adverse events $\geq$ Grade 3 were not observed.

\section{Discussion}

Here we aimed to analyze the treatment outcomes and prognostic markers, including immune and inflammatory factors, of postoperative RT of patients with CCA and to confirm the safety and efficacy of postoperative RT. Adjuvant therapy for CCA is controversial, and there are several options such as adjuvant chemotherapy alone, concurrent chemoradiotherapy, and radiation therapy alone. Further, if the resection margin is $\mathrm{R} 0$, careful observation is required. Patients who receive adjuvant chemotherapy alone after surgery experience MSTs ranging from 51.162 months $[23,24,25]$. However, in three of the studies, the margin status was R0 or R1, and R0 accounted for the majority of patients. The 2year OS and MST rates of patients who receive adjuvant chemoradiotherapy or radiation therapy range from 57.9-60\% and 30.2-36.9 months, respectively $[4,26,27,28,29]$. In these reports, only R0 or R1 patients were included, and the median radiation doses ranged from $45-59.4 \mathrm{~Gy}$, and $28-100 \%$ of patients received concurrent chemotherapy.

Patients with unresectable extrahepatic cholangiocarcinoma (EHCC) treated with radiation therapy using 3D-CRT, intensity-modulated radiation therapy (IMRT), or proton beam therapy experience an MST of 18.7 months [1]. In our present study, 2-year OS rates were 59.5\%; those of CSS, PFS, and LRC were $62.0 \%, 40.1 \%$, and $66.7 \%$, respectively; and MST was 29.5 months. Considering our patients' characteristics (e.g. R1 or R2 margin) and that only eight patients received concurrent chemotherapy, these results are consistent with those of previous reports [3, 23-29]. In the current study, 19 patients (32.2\%) developed local recurrence, with or without distant metastases. The most frequent sites of local recurrence were the hepatectomy stump, the anastomosis, or both. Several reports that determined the sites of local recurrence with or without adjuvant chemotherapy found that the most common are biliary anastomosis, the liver incision, and choledochojejunostomy, with recurrence rates ranging from $36.4-59 \%[1,30,31]$. Thus, the frequencies of local recurrence sites are similar with or without RT; however, our present data indicate that the recurrence rates were lower for patients administered adjuvant RT. Moreover, 31 (52.5\%) patients died of cancer, and 27 (87.1\%) who died had distant metastasis. In 20 of these 31 patients, distant metastases were detected as a first recurrence. Therefore, distant metastasis critically influences the outcomes of patients with CCA.

Immune and inflammatory responses attract attention because they are critical for tumor development and are potentially associated with treatment outcomes. Most studies report that an elevated NLR before initial surgery, chemotherapy, or RT, or combined, is associated with poor prognoses of patients with lung cancer, uterine cervical cancer, ovarian cancer, and many other solid tumors [17, 18, 19, 20]. In CCA, an elevated NLR immediately before surgery or chemotherapy potentially predicts shorter PFS and OS [1, 32-35]. In EHCC, the NLR is not significantly associated with PFS, CSS, or OS, although an elevated PLR is significantly associated with shorter PFS and OS [36]. Here, when we analyzed the data immediately before RT, but not before initial treatment, the NLR and PLR were not significantly associated with treatment outcomes. Only LCR $\leq$ median value was significantly associated with longer PFS, as indicated by univariate and multivariate analyses $(p=0.004$, and $p=$ 0.023 , respectively).

Lymphocytes are required for the inflammatory response and contribute to the adaptive immune system, including immunosurveillance. It is conceivable that one of many cells involved in the tumor microenvironment play an important role in the defense against cancer [17, 20].

Page $4 / 12$ 
Radiation-induced lymphopenia correlates with survival and prognosis. For example, in postoperative RT for breast cancer, radiation-induced lymphopenia predicts poorer prognosis [37], and radiation-induced lymphopenia correlates with decreased OS of patients with various cancers administered PD-1-directed immune checkpoint inhibitors and palliative RT [38]. In contrast, the G3-G4 nadir of the absolute lymphocyte count is associated with longer PFS and LRFS of patients with nasopharyngeal carcinoma [39]. Further, adjuvant chemotherapy causes lymphopenia, which is not associated with shorter survival [20]. Thus, the correlation of lymphocytes with survival and prognosis is controversial. Note that analysis of lymphocyte subsets (CD8+, CD4+) may help resolve this controversy [41]. Therefore, further investigation is required.

To our knowledge, this is the first report to analyze postoperatively and immediately before RT, prognostic markers, including immune and inflammatory factors of patients with CCA. Comparisons with previous studies may be difficult because of their different populations and stages. Patients with an elevated NLR experience shorter survival [1,33-35]. However, we show a significant association between LCR and PFS. These differences may be explained as follows: 1) This analysis was performed after surgery with or without chemotherapy. 2) Lymphocytes play an important role in immune and inflammatory systems. CCA often causes inflammation around the biliary tract. Therefore, the immune and inflammatory responses of patients with CCA may have already been stimulated and therefore exhibit different dynamics. In the present study, age $\geq 75, \mathrm{~N}+$, and LCR were prognostic factors of survival. Combined with previous studies, positive lymph nodes are the most significant predictive factors for surgery with curative intent, with or without (chemo)radiotherapy [30, 31, 37]. Age is a prognostic factor for CCA [1]. Moreover, some studies show that tumor size and multiple tumors (satellite tumor) are prognostic factors of CCA [1, 30, 31]. In the present study, there was no significant difference in tumor size (data not shown), and patients did not have detectable satellite tumors.

In the present study, only hematologic toxicity $\geq$ Grade 3 was observed, which was manageable. In particular, patients with Grade 4 toxicity received chemotherapy before or after RT, or both, which does not exclude the possibility that chemotherapy contributed. The rates of acute adverse events are consistent with those of our previous research [10]. When we re-evaluated the CP scores, those of 11 patients (18.6\%) decreased after RT, and no patient was considered Class C immediately after RT. Two patients had possible therapy-related liver toxicity, and they received chemotherapy before and after RT (TS-1 and GEM) but not concurrent chemotherapy. One patient's CP score decreased from B7 to $\mathrm{B} 8$, the score of the other did not change (A6) immediately before or after RT. The change of the CP score was minimal in these patients. Therefore, it may be difficult to predict therapy-related liver toxicity using the change of CP immediately before and after RT. We must therefore consider the effects of chemotherapy. Further research and long-term observations are required to predict therapy-related liver toxicity.

Limitations

This study has several limitations, including its retrospective design, the small number of patients, and the short median follow-up.

\section{Conclusions}

Postoperative RT for CCA led to acceptable intermediate-term outcomes and tolerance. Multivariate analysis revealed that N+ significantly correlated with OS, PFS, and CSS, and a lower LCR immediately before RT and was significantly associated with PFS. However, further studies are required to determine long-term efficacy and late toxicities.

\section{Declarations}

\section{Conflict of interest:}

The authors declare that they have no conflict of interests.

\section{Ethics approval and consent to participate:}

The Institutional Review Board (IRB) of Yokohama City University approved this study. The ethical committee approval number is B191100004. Written informed consent of using patients' data was obtained before the treatment.

\section{Consent for publication:}

Consent of publication was obtained using our institutional consent form.

\section{Availability of data and materials:}

The datasets used and/or analysed during the current study are available from the corresponding author on reasonable request.

\section{Acknowledgments:}

Not applicable 


\section{References}

1. Elganainy D, Holliday EB, Taniguchi CM, Smith GL, Shroff R, Javle M, Raghav K, Kaseb A, Aloia TA, Vauthey JN, Tzeng CD, Herman JM, Koong AC, Krishnan SX, Minsky BD, Crane CH, Das P, Koay EJ. Dose escalation of radiotherapy in unresectable extrahepatic cholangiocarcinoma. Cancer Med. 2018; 7:4880-4892.

2. Howlader N, Noone AM, Krapcho M. Previous Version: SEER Cancer Statistics Review, 1975-2013, http://seer.cancer.gov/csr/1975_2013/, based on November 2015 SEER data submission, posted to the SEER web site, April 2016.

3. Hoehn RS, Wima K, Ertel AE, Meier A, Ahmad SA, Shah SA, Abbott DE. Adjuvant Chemotherapy and Radiation Therapy is Associated with Improved Survival for Patients with Extrahepatic Cholangiocarcinoma. Ann Surg Oncol 2015; 22: S1133-1139.

4. Dover LL, Oster RA, McDonald AM, DuBay DA, Wang TN, Jacob R. Impact of adjuvant chemoradiation on survival in patients with resectable cholangiocarcinoma. HPB (Oxford) 2016;18: 843-850.

5. Williams TM, Majithia L, Wang SJ, Thomas CR. Defining the role of adjuvant therapy: cholangiocarcinoma and gall bladder cancer. Semin Radiat Oncol. 2014;24: 94-104.

6. Shroff RT, Kennedy EB, Bachini M, Bekaii-Saab T, Crane C, Edeline J, El-Khoueiry JA, Feng M, Katz MHG, Primrose J, Soares HP, Valle J, Maithel SK. Adjuvant therapy for resected biliary tract cancer: ASCO clinical practice guideline. Journal of Clinical oncology, 2019; 37:10151027.

7. Horgan AM, Amir E, Walter T, Knox JJ. Adjuvant therapy in the treatment of biliary tract cancer: A systematic review and meta-analysis. J Clin Oncol, 2012; 30:1934-1940.

8. Ma KW, Cheung TT, Leung B, She BWH, Chok KSH, Chan ACY, Dai WC, Lo CM. Adjuvant chemotherapy improves oncological outcomes of resectable intrahepatic cholangiocarcinoma: A meta-analysis. Medicine (Baltimore). 2019; 98: e14013.

9. National Comprehensive Cancer Network Clinical Practice Guidelines in Oncology (NCCN Guidelines $\left.{ }^{\circledR}\right)$. https://www.nccn.org/professionals/physician_gls/default.aspx, Accessed 25 September 2020.

10. Mukai Y, Matsuyama R, Koike I, Kumamoto T, Kaizu H, Homma Y, Takano S, Sawada Y, Sugiura M, Yabushita Y, Ito E, Sato M, Endo I, Hata M. Outcome of postoperative radiation therapy for cholangiocarcinoma and analysis of dose-volume histogram of remnant liver. Medicine (Baltimore). 2019; 98:e16673.

11. Vern-Gross TZ, Shivnani AT , Chen K, Lee CM , Tward JD , MacDonald OK, Crane CH, Talamonti MS, Munoz LL, Small Jr W. Survival outcomes in resected extrahepatic cholangiocarcinoma: effect of adjuvant radiotherapy in a surveillance, epidemiology, and end results analysis. International Journal of Radiation Oncology*Biology*Physics 2011; 81: 189-98.

12. Hughes MA, Frassica DA, Yeo CJ , Riall TS , Lillemoe KD , Cameron JL, Donehower RC, Laheru DA, Hruban RH, Abrams RA. Adjuvant concurrent chemoradiation for adenocarcinoma of the distal common bile duct. International Journal of Radiation Oncology*Biology*Physics 2007; 68: 178-82.

13. Goodman KA, Regine WF , Dawson LA, Ben-Josef E , Haustermans K, Bosch WR, Turian J, Abrams RA. Radiation therapy Oncology Group consensus panel guidelines for the delineation of the clinical target volume in the postoperative treatment of pancreatic head cancer. International Journal of Radiation Oncology*Biology*Physics 2012; 83: 901-8.

14. Gil E, Joh JW, Park HC, Yu JI, Jung SH, Kim JM. Predictors and patterns of recurrence after curative liver resection in intrahepatic cholangiocarcinoma, for application of postoperative radiotherapy: A retrospective study. World J Surg Oncol,2015; 13: 227

15. Hyder O, Hatzaras I, Sotiropoulos GC, Paul A, Alexandrescu S, Marques H, Pulitano C, Barroso E, Clary BM, Aldrighetti L, Ferrone CR, Zhu AX, Bauer TW, Walters DM, GroeschI R, Gamblin RC, Marsh JW, Nguyen KT, Turley R, Popescu I, Hubert C, Meyer S, Choti MA, Gigot JF, Mentha G, Pawlik TM. Recurrence after operative management of intrahepatic cholangiocarcinoma. Surgery,2013; 153: 811-818

16. Horgan AM, Amir E, T. Walter T, Knox JJ. Adjuvant therapy in the treatment of biliary tract cancer: A systematic review and meta-analysis. J Clin Oncol, 2012; 30: 1934-1940

17. Sebastian N, Wu T, Bazan J, Driscoll E, Willers H, Yegya-Raman N, Bond L, Dwivedi A, Mo X, Tan Y, Xu-Welliver M, Haglund K, Jabbour SK, Keane FK, Williams TM. Pre-treatment neutrophil-lymphocyte ratio is associated with overall mortality in localized non-small cell lung cancer treated with stereotactic body radiotherapy. Radiotherapy and oncology 2019: 134:151-157.

18. Milne K, Alexander C, Webb JR, Sun W, Dillon K, Kalloger SE, Gilks CB, Clarke B, Köbel M, Nelson BH. Absolute lymphocyte count is associated with survival in ovarian cancer independent of tumor-infiltrating lymphocytes. J Transl Med. $2012 ; 10: 33$

19. Howard R, Kanetsky PA, Egan KM. Exploring the prognostic value of the neutrophil-to-lymphocyte ratio in cancer. Scientific reports, 2019 ;9(1):19673

20. Contreras JA, Lin AJ, Weiner A, Speirs C, Samson P, Mullen D, Campian J, Bradley J, Roach M, Robinson C. Cardiac dose is associated with immunosuppression and poor survival in locally advanced NSCLC. Radiotherapy and Oncology 2018;128(3):498-504. 
21. Response Evaluation Criteria in Solid Tumors (RECIST ver. 1.1),

URL: https://recist.eortc.org/recist-1-1-2/. Accessed 25 September 2020

22. The Common Terminology Criteria for Adverse Events (CTCAE) v4.03.

URL: https://ctep.cancer.gov/protocolDevelopment/electronic_applications/ctc.htm\#ctc_40.

Accessed 25 September 2020

23. Primrose JN, Fox R, Palmer DH, Prasad R, Mirza D, Anthoney DA. Adjuvant capecitabine for biliary tract cancer: The BILCAP randomized study. J Clin Oncol, 2017; 35: suppl 15; abstr 4006

24. Edeline J, Bonnetain F, Phelip JM, Watelet J, Hammel P, Joly JP, Benabdelghani M, Fartoux L, Bouhier-Leporrier K, Jouve JL, Faroux R, Guerin-Meyer V, Assenat E, Seitz JF, Malka D, Louvet C, Bertaut A, Juzyna B, Stanbury T, BoucherE. Adjuvant GEMOX for biliary tract cancer: Updated relapse-free survival and first overall survival results of the randomized PRODIGE 12-ACCORD 18 (UNICANCER GI) phase III trial. Ann Oncol. 2017; 28:605-649

25. Ebata T, Hirano S, Konishi M, Uesaka K, Tsuchiya Y, Ohtsuka M, Kaneoka Y, Yamamoto M, Ambo Y, Shimizu Y, Ozawa F, Fukutomi A, Ando M, Nimura Y, Nagino M, Bile Duct Cancer Adjuvant Trial (BCAT) Study Group. Randomized clinical trial of adjuvant gemcitabine chemotherapy versus observation in resected bile duct cancer. Br J Surg 2018; 105:192-202

26. Bentzen SM, Constine LS, Deasy JO, Eisbruch A, Jackson A, Marks LB, Haken RKT, Yorke ED. Quantitative Analyses of Normal Tissue Effects in the Clinic (QUANTEC): An Introduction to the Scientific Issues. Int J Radiat Oncol Biol Phys 2010;76(3 Suppl): S3-S9.

27. Gerhards MF, van Gulik TM, González González D, Rauws EAJ, Gouma DJ. Results of postoperative radiotherapy for resectable hilar cholangiocarcinoma. World J Surg 2003;27: 173-179.

28. Ben-Josef E, Guthrie KA, El-Khoueiry AB, Corless CL, Zalupski MM, Lowy AM, Thomas Jr CR, Alberts SR, Dawson LA, Micetich KC, Thomas MB, Siegel AB, Blanke CD. SWOG S0809: A phase II intergroup trial of adjuvant capecitabine and gemcitabine followed by radiotherapy and concurrent capecitabine in extrahepatic cholangiocarcinoma and gallbladder carcinoma. J Clin Oncol. 2015; 33:2617-2622.

29. Lee J, Kang SH, Noh OK, Chun M, Y-T Oh, B-W Kim, S-W Kim. Adjuvant concurrent chemoradiation therapy in patients with microscopic residual tumor after curative resection for extrahepatic cholangiocarcinoma. Clinical and translational oncology. 2018; 20(8):1011-1017.

30. Ghiassi-Nejad Z, Tarchi P, Moshier E, Ru M, Tabrizian P, Schwartz M, Buckstein M. Prognostic factors and patterns of locoregional failure after surgical resection in patients with cholangiocarcinoma without adjuvant radiation therapy:optimal field design for adjucant radiation therapy. Int J Radiat Oncol Biol Phys. 2017 ;99(4):805-811.

31. Jung W, Kim K, Min SK, Nam EM, Lee JK. Mapping of local recurrence after pancreaticoduodenectomy for distal extrahepatic cholangiocarcinoma: implications for adjuvant radiotherapy. Br J Radiol. 2019 ;92(1100):20190285.

32. Cheng Q, Luo X, Zhang B, Jiang X, Yi B, Wu M. Predictive Factors for Prognosis of Hilar Cholangiocarcinoma: Postresection Radiotherapy Improves Survival. Eur J Surg Oncol. 2007;33(2):202-7.

33. Ecker BL, Vining CC, Roses RE, Maggino L, Lee MK, Drebin JA, Fraker DL, Vollmer Jr CM, Datta J. Identification of Patients for Adjuvant Therapy After Resection of Carcinoma of the Extrahepatic Bile Ducts: A Propensity Score-Matched Analysis. Ann Surg Oncol. 2017 ;24(13):3926-3933.

34. Buyuksimsek M, Kidi MM, Ogul A, Mirili C, Paydas S. The Effect of Inflammatory Markers on Survival in Advanced Biliary Tract Carcinoma Treated with Gemcitabine/Oxaliplatin Regimen. J Gastrointest Cancer. 2020; 18. Online ahead of print.

35. Suzuki Y, Kan M, Kimura G, Umemoto K, Watanabe K, Sasaki M, Takahashi H, Hashimoto Y, Imaoka H, Ohno I, Mitsunaga S, Ikeda M. Predictive factors of the treatment outcome in patients with advanced biliary tract cancer receiving gemcitabine plus cisplatin as first-line chemotherapy. J Gastroenterol. 2019;54(3):281-290.

36. Kitano Y, Yamashita YI, Yamamura K, Arima K, Kaida T, Miyata T, Nakagawa S, Mima K, Imai K, Hashimoto D, Chikamoto A, Baba H. Effect of preoperative neutrophil-to-lymphocyte and Platelet-to-lymphocyte rations on survival in patients with extrahepatic cholangiocarcinoma Anticancer Res. 2017; 37(6):3229-3237.

37. Sun G, Wang S, Song Y, Jin J, Wang W, Liu Y, Ren H, Fang H, Tang Y, Zhao X, Song Y, Yu Z, Liu X, Li Y. Radiation-induced lymphopenia predicts poorer prognosis in patients with breast cancer: a post Hoc analysis of randomized controlled trial of postmastectomy hypofractionated radiation therapy. Int J Radiat Oncol Biol Phys. 2020; S0360-3016(20)30883-X.

38. Pike LRG, Bang A, Mahal BA, Taylor A, Krishnan M, Spektor A, Cagney DN, Aizer AA, Alexander BM, Rahma O, Balboni T, Ott PA, Hodi FS, Schoenfeld JD. The Impact of Radiation Therapy on Lymphocyte Count and Survival in Metastatic Cancer Patients Receiving PD-1 Immune Checkpoint Inhibitors. Int J Radiat Oncol Biol Phys. 2019;103(1):142-151.

39. Xie X, Gong S, Jin H, Yang P, Xu T, Cai Y, Guo C, Zhang R, Lou F, Yang W, Wang H. Radiation-induced Lymphopenia Correlates With Survival in Nasopharyngeal Carcinoma: Impact of Treatment Modality and the Baseline Lymphocyte Count. Radiat Oncol. 2020;15(1):65.

\section{Tables}

Page $7 / 12$ 
Table 1

Patient and treatment related characteristics.

\begin{tabular}{|c|c|}
\hline Total number of patients & 59 \\
\hline \multicolumn{2}{|l|}{ Gender } \\
\hline Male & $42(71.2 \%)$ \\
\hline Female & $17(28,8 \%)$ \\
\hline \multicolumn{2}{|l|}{ Age (years) } \\
\hline Median (range) & $70(32-87)$ \\
\hline \multicolumn{2}{|l|}{ PS (ECOG) } \\
\hline 0 & $48(81.4 \%)$ \\
\hline 1 & $9(15.3 \%)$ \\
\hline 2 & $2(3.3 \%)$ \\
\hline \multicolumn{2}{|l|}{ Histology } \\
\hline Adenocarcinoma & $56(94.9 \%)$ \\
\hline Cholangiocarcinoma & $3(5.1 \%)$ \\
\hline \multicolumn{2}{|l|}{ Primary tumor site } \\
\hline IHCC & $5(8.5 \%)$ \\
\hline EHCC & $54(91.5 \%)$ \\
\hline \multicolumn{2}{|c|}{ Postoperative stage (TNM Classification of Malignant Tumors, 8th edition) } \\
\hline Stage IA, B & $8(13.6 \%)$ \\
\hline Stage IIA, B & $25(42.4 \%)$ \\
\hline Stage IIIA, B & $15(25.4 \%)$ \\
\hline Stage IVA & $11(18.6 \%)$ \\
\hline \multicolumn{2}{|c|}{ Regional lymph node metastases } \\
\hline Positive & $27(45.8 \%)$ \\
\hline Negative & $32(54.2 \%)$ \\
\hline $\begin{array}{l}\text { Type of resection / operat } \\
\text { Lobectomy } \\
\text { Extended lobectomy } \\
\text { Lobectomy + PD } \\
\text { PD }\end{array}$ & $\begin{array}{l}34(57.6 \%) \\
11(18.6 \%) \\
5(8.5 \%) \\
9(15.3 \%)\end{array}$ \\
\hline \multicolumn{2}{|l|}{ Pathological margin status } \\
\hline RO & 0 \\
\hline $\mathrm{R} 1$ & $27(45.8 \%)$ \\
\hline $\mathrm{R} 2$ & $32(54.2 \%)$ \\
\hline
\end{tabular}

PS: performance status, ECOG: Eastern Cooperative Oncology Group, IHCC: intrahepatic cholangiocarcinoma, EHCC: extrahepatic cholangiocarcinoma, PD: pancreaticoduodenectomy, R0: negative margin, R1: microscopic positive margin, R2: macroscopic positive margin 
Table 2

Chemotherapy

\section{The phase of chemotherapy/Treatment timing $\mathrm{N}$}

\begin{tabular}{|c|c|c|}
\hline (a) neoadjuvant & 16 & GEM $(n=8), \operatorname{GEM}+\operatorname{TS}-1(n=5), \operatorname{GEM}+\operatorname{CDDP}(n=3)$ \\
\hline (b) postoperative, before RT & 19 & $\begin{array}{l}\text { GEM }(n=14), \text { TS- } 1(n=3) \\
\text { GEM + TS- } 1(n=1), \operatorname{GEM}+\operatorname{CDDP}(n=1)\end{array}$ \\
\hline (c) postoperative, concurrent with RT & 8 & $\operatorname{GEM}(n=2), \operatorname{TS}-1(n=6)$ \\
\hline (d) postoperative, after RT & 24 & $\begin{array}{l}\text { GEM }(n=10), \text { TS-1 }(n=6) \\
\text { GEM + TS-1 }(n=4), \text { GEM + CDDP }(n=4)\end{array}$ \\
\hline No chemotherapy from (a) to (d) & 13 & \\
\hline
\end{tabular}

GEM: gemcitabine, TS-1: tegafur/gimeracil/oteracil, CDDP: cisplatin

In the (a) to (d), some of the patients were overrated. 
Table 3-1

Univariate analysis for prognostic factors

\begin{tabular}{|c|c|c|c|c|c|c|c|c|c|c|c|c|c|}
\hline \multirow[t]{3}{*}{ Variables } & & \multicolumn{4}{|c|}{ os } & \multicolumn{2}{|l|}{ CSS } & \multicolumn{3}{|c|}{ PFS } & \multicolumn{3}{|c|}{ LRC } \\
\hline & & HR & $95 \%$ & & HR & $95 \%$ & & HR & $95 \%$ & $\mathbf{P}$ & HR & $95 \%$ & $\mathbf{P}$ \\
\hline & & & $\mathrm{Cl}$ & value & & $\mathrm{Cl}$ & value & & $\mathrm{Cl}$ & value & & $\mathrm{Cl}$ & value \\
\hline \multirow[t]{2}{*}{ Age, years } & $<75$ & 1/reference & & & 1 & & & 1 & & & 1 & & \\
\hline & $\geq 75$ & 2.38 & $\begin{array}{l}1.10- \\
4.83\end{array}$ & 0.028 & 2.07 & $\begin{array}{l}0.89- \\
4.41\end{array}$ & 0.088 & 1.46 & $\begin{array}{l}0.64- \\
3.07\end{array}$ & 0.36 & 1.51 & $\begin{array}{l}0.48- \\
4.06\end{array}$ & 0.45 \\
\hline \multirow[t]{2}{*}{ ECOG PS } & 0 & 1 & & & 1 & & & 1 & & & 1 & & \\
\hline & $>1$ & 2.02 & $\begin{array}{l}0.89- \\
4.15\end{array}$ & 0.086 & 1.94 & $\begin{array}{l}0.82- \\
4.13\end{array}$ & 0.13 & 1.60 & $\begin{array}{l}0.68- \\
3.34\end{array}$ & 0.26 & 1.46 & $\begin{array}{l}0.42- \\
3.98\end{array}$ & 0.52 \\
\hline \multirow[t]{2}{*}{ T category } & $\leq \mathrm{T} 3$ & 1 & & & 1 & & & 1 & & & 1 & & \\
\hline & $>\mathrm{T} 4$ & 1.78 & $\begin{array}{l}0.79- \\
4.82\end{array}$ & 0.17 & 2.16 & $\begin{array}{l}0.85- \\
7.29\end{array}$ & 0.11 & 1.58 & $\begin{array}{l}0.73- \\
3.94\end{array}$ & 0.26 & 1.44 & $\begin{array}{l}0.47- \\
3.75\end{array}$ & 0.49 \\
\hline \multirow[t]{2}{*}{$\mathrm{N}$ category } & NO & 1 & & & 1 & & & 1 & & & 1 & & \\
\hline & $\mathrm{N}+$ & 1.96 & $\begin{array}{l}1.05- \\
3.69\end{array}$ & 0.034 & 2.11 & $\begin{array}{l}1.08- \\
4.17\end{array}$ & 0.028 & 1.79 & $\begin{array}{l}0.95- \\
2.43\end{array}$ & 0.073 & 1.80 & $\begin{array}{l}0.74- \\
4.51\end{array}$ & 0.19 \\
\hline \multirow{2}{*}{$\begin{array}{l}\text { Chemotherapy } \\
\text { at least once }\end{array}$} & $>1$ & 1 & & & 1 & & & 1 & & & 1 & & \\
\hline & 0 & 2.20 & $\begin{array}{l}0.99- \\
5.88\end{array}$ & 0.053 & 2.27 & $\begin{array}{l}0.97- \\
6.69\end{array}$ & 0.063 & 1.90 & $\begin{array}{l}0.86- \\
5.05\end{array}$ & 0.12 & 0.86 & $\begin{array}{l}0.33- \\
2.65\end{array}$ & 0.77 \\
\hline \multirow[t]{2}{*}{ Liver resection } & No & 1 & & & 1 & & & 1 & & & 1 & & \\
\hline & resection & 1.05 & $\begin{array}{l}0.51- \\
2.04\end{array}$ & 0.88 & 1.07 & $\begin{array}{l}0.50- \\
2.15\end{array}$ & 0.85 & 0.99 & $\begin{array}{l}0.49- \\
1.90\end{array}$ & 0.98 & 0.79 & $\begin{array}{l}0.26- \\
2.04\end{array}$ & 0.64 \\
\hline \multirow{2}{*}{$\begin{array}{l}\text { Surgical } \\
\text { margin status }\end{array}$} & $\mathrm{R} 1$ & 1 & & & 1 & & & 1 & & & 1 & & \\
\hline & $\mathrm{R} 2$ & 1.26 & $\begin{array}{l}0.59- \\
3.12\end{array}$ & 0.58 & 1.37 & $\begin{array}{l}0.61- \\
3.66\end{array}$ & 0.47 & 1.53 & $\begin{array}{l}0.72- \\
3.79\end{array}$ & 0.28 & 1.64 & $\begin{array}{l}0.55- \\
7.04\end{array}$ & 0.40 \\
\hline \multirow[t]{2}{*}{$\mathrm{Hb}$} & >median & 1 & & & 1 & & & 1 & & & 1 & & \\
\hline & $\leq$ median & 0.95 & $\begin{array}{l}0.51- \\
1.76\end{array}$ & 0.86 & 0.99 & $\begin{array}{l}0.51- \\
1.94\end{array}$ & 0.99 & 0.86 & $\begin{array}{l}0.46- \\
1.61\end{array}$ & 0.64 & 0.63 & $\begin{array}{l}0.25- \\
1.52\end{array}$ & 0.31 \\
\hline \multirow[t]{2}{*}{ Platelet } & >median & 1 & & & 1 & & & 1 & & & 1 & & \\
\hline & $\leq$ median & 1.29 & $\begin{array}{l}0.69- \\
2.40\end{array}$ & 0.43 & 1.50 & $\begin{array}{l}0.78^{-} \\
2.95\end{array}$ & 0.23 & 1.57 & $\begin{array}{l}0.85- \\
2.97\end{array}$ & 0.152 & 1.41 & $\begin{array}{l}0.58- \\
3.51\end{array}$ & 0.45 \\
\hline \multirow[t]{2}{*}{ LCR } & >median & 1 & & & 1 & & & 1 & & & 1 & & \\
\hline & $\leq$ median & 0.64 & $\begin{array}{l}0.35- \\
1.19\end{array}$ & 0.16 & 0.60 & $\begin{array}{l}0.31- \\
1.15\end{array}$ & 0.12 & 0.53 & $\begin{array}{l}0.28- \\
0.99\end{array}$ & 0.045 & 1.07 & $\begin{array}{l}0.44- \\
2.73\end{array}$ & 0.89 \\
\hline \multirow[t]{2}{*}{ NLR } & >median & 1 & & & 1 & & & 1 & & & 1 & & \\
\hline & $\leq$ median & 1.56 & $\begin{array}{l}0.80- \\
3.29\end{array}$ & 0.19 & 1.43 & $\begin{array}{l}0.71- \\
3.11\end{array}$ & 0.33 & 1.50 & $\begin{array}{l}0.77- \\
3.15\end{array}$ & 0.24 & 0.83 & $\begin{array}{l}0.34- \\
2.12\end{array}$ & 0.69 \\
\hline \multirow[t]{2}{*}{ PLR } & >median & 1 & & & 1 & & & 1 & & & 1 & & \\
\hline & $\leq$ median & 1.15 & $\begin{array}{l}0.61- \\
2.13\end{array}$ & 0.66 & 1.31 & $\begin{array}{l}0.67- \\
2.54\end{array}$ & 0.42 & 1.43 & $\begin{array}{l}0.77- \\
2.67\end{array}$ & 0.26 & 1.01 & $\begin{array}{l}0.40- \\
2.46\end{array}$ & 0.98 \\
\hline
\end{tabular}


Table 3-2

Multivariate analysis for prognostic factors

\begin{tabular}{|c|c|c|c|c|c|c|c|c|c|}
\hline \multirow[t]{3}{*}{ Variables } & \multicolumn{3}{|l|}{ os } & \multicolumn{3}{|c|}{ CSS } & \multicolumn{3}{|c|}{ PFS } \\
\hline & HR & $95 \%$ & $P$ & HR & $95 \%$ & $P$ & HR & $95 \%$ & $P$ \\
\hline & & $\mathrm{Cl}$ & value & & $\mathrm{Cl}$ & value & & $\mathrm{Cl}$ & value \\
\hline
\end{tabular}

\begin{tabular}{|c|c|c|c|c|c|c|c|c|c|c|}
\hline Age, years & $<75$ & 1 & & & 1 & & & 1 & & \\
\hline & $\geq 75$ & 2.09 & $\begin{array}{l}0.96- \\
4.27\end{array}$ & 0.051 & 1.75 & $\begin{array}{l}0.75- \\
3.78\end{array}$ & 0.18 & 1.30 & $\begin{array}{l}0.56- \\
2.78\end{array}$ & 0.52 \\
\hline \multirow[t]{2}{*}{$\mathrm{N}$ category } & NO & 1 & & & 1 & & & 1 & & \\
\hline & $\mathrm{N}+$ & 1.96 & $\begin{array}{l}1.03- \\
3.73\end{array}$ & 0.037 & 2.13 & $\begin{array}{l}1.08- \\
4.23\end{array}$ & 0.028 & 1.96 & $\begin{array}{l}1.02- \\
3.84\end{array}$ & 0.045 \\
\hline \multirow[t]{2}{*}{ TLR } & >median & 1 & & & 1 & & & 1 & & \\
\hline & $\leq$ median & 0.63 & $\begin{array}{l}0.34- \\
1.19\end{array}$ & 0.15 & 0.58 & $\begin{array}{l}0.29- \\
1.14\end{array}$ & 0.11 & 0.48 & $\begin{array}{l}0.25- \\
0.91\end{array}$ & 0.023 \\
\hline
\end{tabular}

OS: overall survival, CSS: cause-specific survival, PFS: progression-free survival, LRC: loco-regional control, HR: Hazard ratio, Cl: confidence interval ECOG PS, Eastern Cooperative Oncology Group performance status, $\mathrm{N}+$ : positive regional lymph node metastases, Hb: hemoglobin, LCR: lymphocyte count ratio, NLR: neutrophil-to-lymphocyte ratio, PLR: platelet-to-lymphocyte ratio

Table 4

Acute Toxicities

\begin{tabular}{|lcccc|}
\hline & Grade 1 & Grade 2 & Grade 3 & Grade 4 \\
\hline Hematology toxicity/ myelosuppression & & & & \\
\hline Leukocytes/ Leukopenia & 18 & 9 & 9 & 0 \\
\hline Neutrophils/absolute neutrophil count & 11 & 6 & 5 & 2 \\
\hline Hemoglobin & 17 & 13 & 1 & 0 \\
\hline Platelets & 9 & 6 & 0 & 1 \\
\hline Gastrointestinal (GI) & & & 0 & 0 \\
\hline Anorexia & 20 & 0 & 0 & 0 \\
\hline Nausea & 2 & 0 & 0 & 0 \\
\hline Diarrhea & 1 & 0 & 0 & 0 \\
\hline Gastritis & 1 & 2 & 0 & 0 \\
\hline Duodenal ulcer & 0 & 1 & 0 & 0 \\
\hline Radiation induced dermatitis & 6 & 0 & 0 & \\
\hline
\end{tabular}

\section{Figures}


Fig1-1

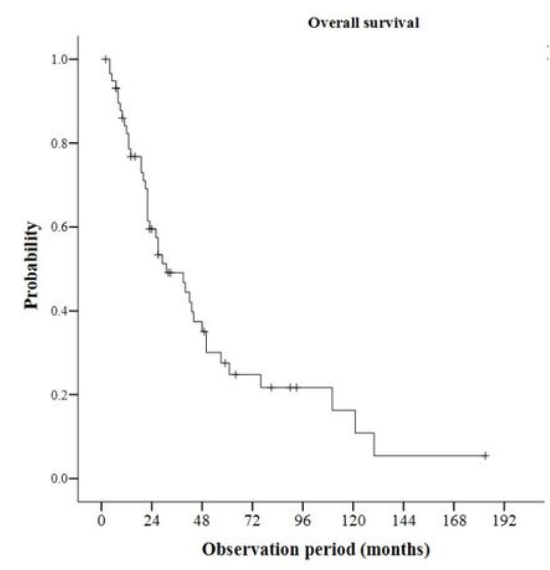

Fig1-3

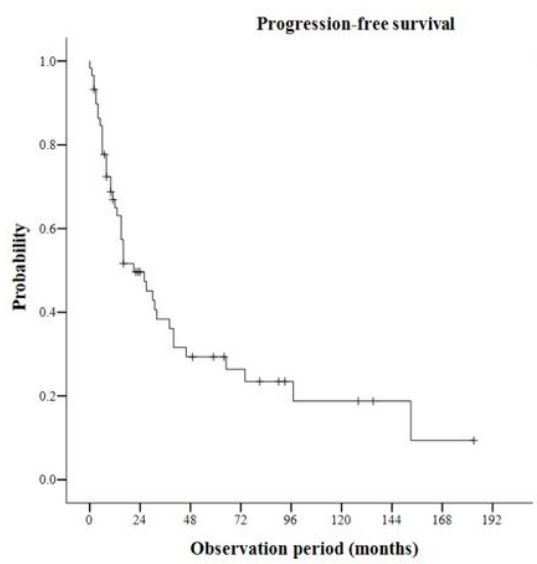

Fig1-2

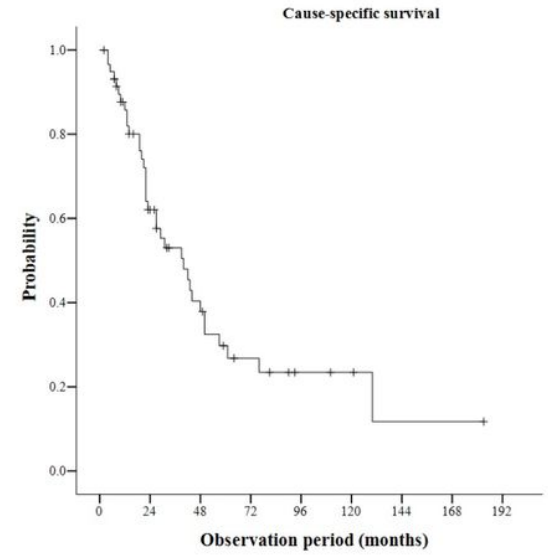

Fig1-4

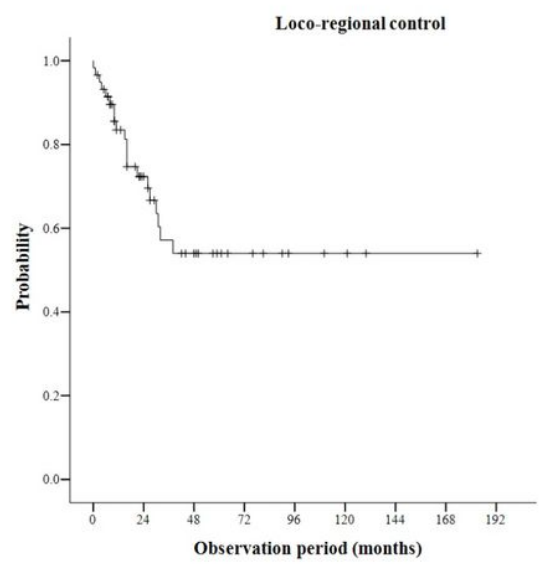

Figure 1

1-1. overall survival 1-2. cause-specific survival 1-3. progression-free survival 1-4. loco-regional control 